\title{
Effect of Heat Treatment on the Microstructure and Corrosión Resistance of AlCoCrFeNi High- Entropy Alloy
}

\author{
Nestor Florido-Suarez ${ }^{1}$, Pedro Socorro-Perdomo ${ }^{1}$, Victor Geanta ${ }^{2}$ and Julia Mirza-Rosca ${ }^{1}$
}

${ }^{1}$ University of Las Palmas de Gran Canaria, United States, ${ }^{2}$ Politehnica University of Bucharest, United States

Introduction In the early 2000s, a distinctly different approach emerged based on conceptually equiatomic or near-equiatomic multicomponent alloys, commonly with five or more metallic elements, which were assumed to form stable single-phase solid solutions [1]. This stability was then attributed to the high entropy of the mixture coupled with a disordered multi-element solution, which was assumed to be in competition with the enthalpy of phase formation. This concept, initially proposed by Yeh et al [2] in Taiwan and separately by Cantor et al [3] in the UK, has come to be called high-entropy alloys (HEA) and has been found to be of great importance in the formulation of new alloys. AlCoCrFeNi is one of the most studied alloy systems from the area of high entropy alloys (HEA) due to it's attractive microstructure and mechanical properties. AlCoCrFeNi alloys are mainly prepared by vacuum arc remelting (VAR), which is based on the remelting of the raw elemental metals by means of the arc generated between the electrode and the metallic powder to be melted. However, arc remelting method requires high energy and the phase composition is not uniform, which is prejudicial to the mechanical properties of the alloy. It is often necessary to homogenize at high temperature and continue hot or cold working, followed by annealing treatment, to disintegrate the microstructure of the melt and thus obtain homogeneous materials with a fine-grained structure [4]. In this work the effect of annealing treatment on the microstructure and corrosion resistance of $\mathrm{AlCoCrFeNi}$ in simulated body fluid is studied for the possible use as new material for nuclear applications. Experimental procedure The alloy AlCoCrFeNi was obtained from high purity powders of $\mathrm{Al}, \mathrm{Cr}, \mathrm{Co}, \mathrm{Fe}$ and $\mathrm{Ni}$ in a MRF ABJ 900 Vacuum Arc Remelting installation. The heat treatment consists of heating the samples at $1100^{\circ} \mathrm{C}$, maintaining them at this temperature during 72 hours and then cooling in water at room temperature. Microstructural characterization with Optical Microscopy (Zeiss AxioVert A1), Scanning Electron Microscopy and Energy-dispersive X-ray Spectroscopy (Fei XL30 ESEM with LaB6 cathode coupled to an EDAX Saphire) was performed. Electrochemical Impedance Spectroscopy (PAR 263A connected with a lock-in amplifier PAR 5210) was used to analyze the behavior of the samples in high concentration salts solutions and the results were correlated with the corrosion potential and the corrosion rate in the same conditions. Results and discussion It can be observed that the overall look of $\mathrm{AlCoCrFeNi}$ without heat treatment (see Fig.1) is polygonal grains with no obvious particles and only small pores and nanoprecipitates are detected. Two different zones are highlighted, one dendritic and other interdendritic with significant compositional differences of the elements. The nanoscale analysis revealed the dendritic region rich in $\mathrm{Al}$ and $\mathrm{Ni}$ but depleted in $\mathrm{Cr}$ and $\mathrm{Fe}$ and the interdendritic region rich in $\mathrm{Cr}$ and $\mathrm{Fe}$ but depleted in $\mathrm{Al}$ and $\mathrm{Ni}$. Only cobalt shows no significant difference in the two areas with a somewhat higher concentration in the interdendritic zone. After heat treatment, a wall-shaped structure is predominant (see Fig.2). Both size and quantity of the precipitates increase, indicating that the heat treatment promote the homogeneous structure formation. The analysis indicates that the nanoscale precipitates are phases with all the elements ( $\mathrm{Ni}, \mathrm{Cr}, \mathrm{Al}, \mathrm{Fe}$ and $\mathrm{Ni}$ ) of nearequimolar ratio and the matrix is $\mathrm{Cr}$ and $\mathrm{Fe}$ rich phase. Because the matrix is the predominant phase and in it the concentration of $\mathrm{Cr}$ is high, the predominant component of the uniform and compact passive film is $\mathrm{Cr} 2 \mathrm{O} 3$ that successfully inhibits the contact of the chloride ions with the metallic surface, thus reducing more than 50 times the corrosion rate and improving the corrosion resistance of the alloy. Electrochemical Impedance Spectroscopy is a very powerful technique to study the corrosion performance of high entropy alloys in a very concentrated salt solution and the obtained results were confirmed by the other 
electrochemical techniques employed in this study. Through all these techniques, information was obtained about the changes of the protective capacity of the passive layers, according with and without the heat treatment of the alloy and the exposure potential. Conclusions The heat treatment has a significant influence on the microstructure and the behavior of the alloys in simulated body fluid. With the heat treatment, the solidified microstructure varies from equiaxed dendritic grain to a wall-shaped structure with nanoprecipitates. The very high resistance of the heat treated alloy implies a high corrosion resistance which can be assigned to the formation of the protective chromium oxide layer. The obtained results demonstrate that the heat treatment alloy fulfill the prerequisites for its use as new material for nuclear applications.

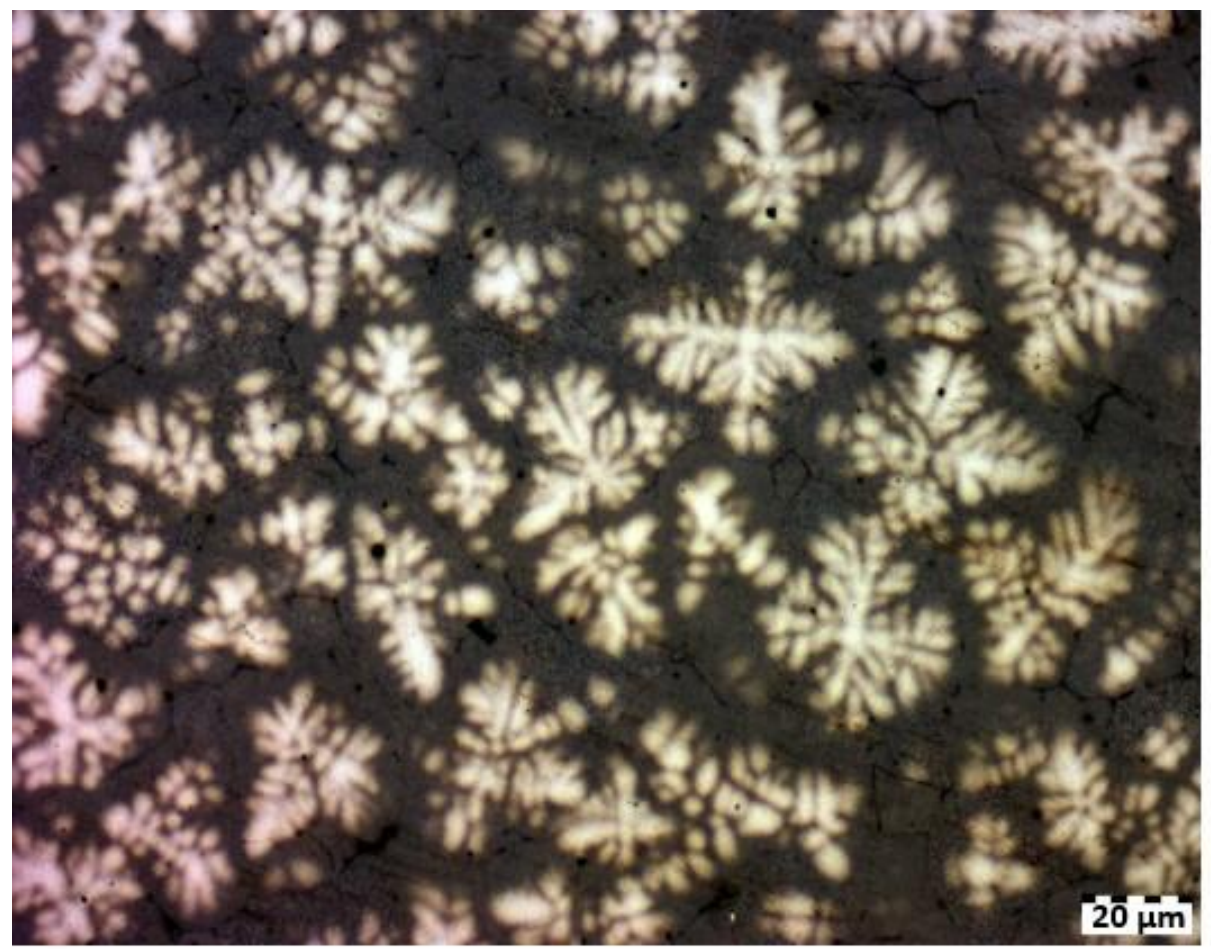

Figure 1. Fig.1 As-cast microstructure of AlCrFeCoNi alloy 


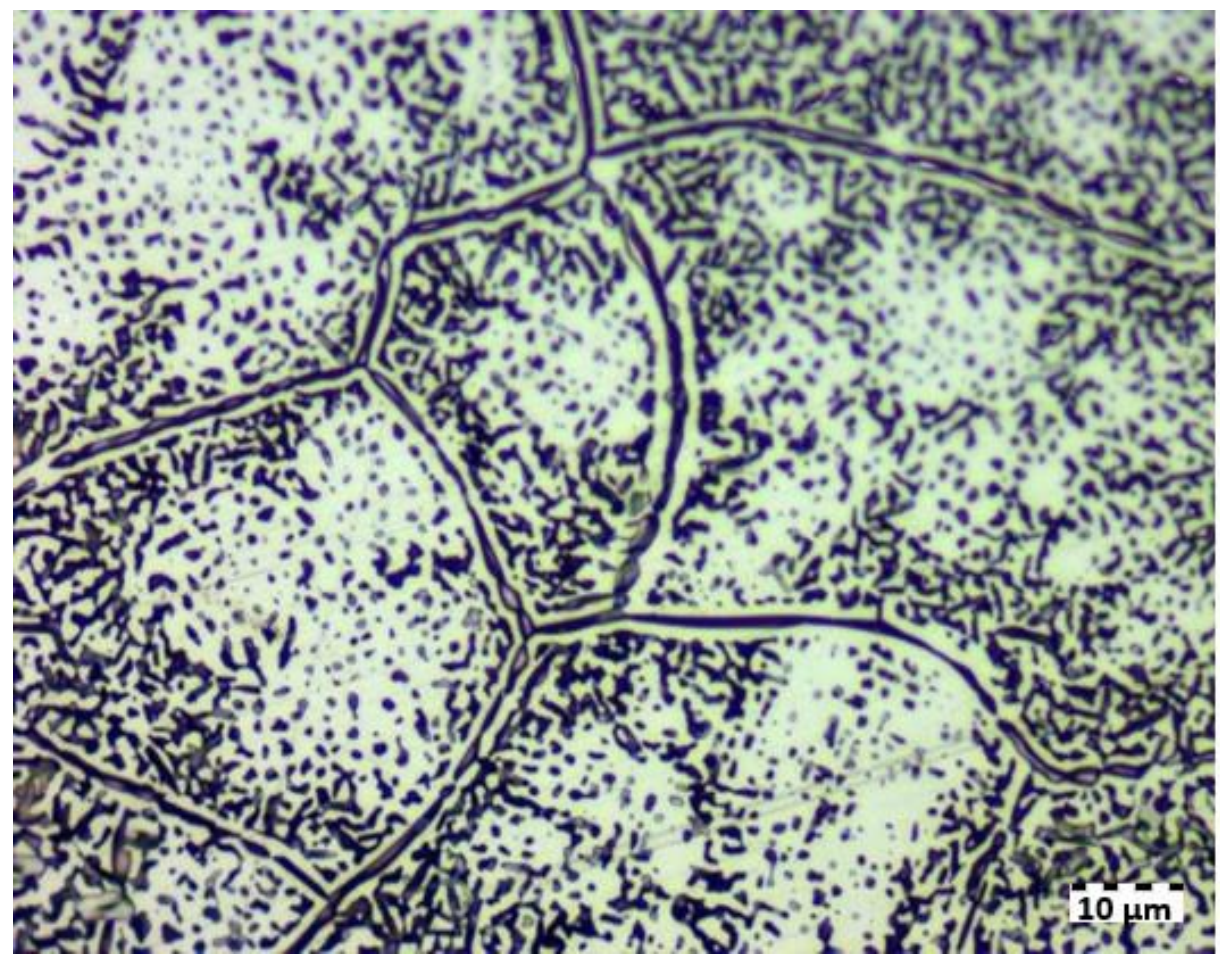

Figure 2. Fig.2 Heat treated microstructure of AlCrFeCoNialloy

\section{References}

[1] Z. Li, S. Zhao, R. O. Ritchie, and M. A. Meyers, "Mechanical properties of high-entropy alloys with emphasis on face-centered cubic alloys," Progress in Materials Science, vol. 102, no. March 2018, pp. 296-345, 2019, doi: 10.1016/j.pmatsci.2018.12.003.

[2] J. W. Yeh et al., "Nanostructured high-entropy alloys with multiple principal elements: Novel alloy design concepts and outcomes," Advanced Engineering Materials, vol. 6, no. 5, pp. 299-303, 2004, doi: 10.1002/adem.200300567.

[3] B. Cantor, I. T. H. Chang, P. Knight, and A. J. B. Vincent, "Microstructural development in equiatomic multicomponent alloys," Materials Science and Engineering A, vol. 375-377, no. 1-2 SPEC. ISS., pp. 213-218, 2004, doi: 10.1016/j.msea.2003.10.257.

[4] López Ríos M, Socorro Perdomo PP, Voiculescu I, Geanta V, Crăciun V, Boerasu I, et al. Effects of nickel content on the microstructure, microhardness and corrosion behavior of high-entropy AlCoCrFeNix alloys. Sci Rep 2020;10:1-11. https://doi.org/10.1038/s41598-020-78108-5. 